\title{
Papers
}

\section{Decision making processes in people with symptoms of acute myocardial infarction: qualitative study}

\author{
Jill Pattenden, Ian Watt, Robert J P Lewin, Neil Stanford
}

\begin{abstract}
Objective To identify the themes that influence decision making processes used by patients with symptoms of acute myocardial infarction.

Design Qualitative study using semistructured interviews.

Setting Two district hospitals in North Yorkshire. Participants 22 patients admitted to hospital with confirmed second, third, or fourth acute myocardial infarction.

Main outcome measure Patients' perceptions of their experience between the onset of symptoms and the decision to seek medical help.

Results Six main themes that influence the decision making process were identified: appraisal of symptoms, perceived risk, previous experience, psychological and emotional factors, use of the NHS, and context of the event.

Conclusions Knowledge of symptoms may not be enough to promote prompt action in the event of an acute myocardial infarction. Cognitive and emotional processes, individual beliefs and values, and the influence of the context of the event should also be considered in individual interventions designed to reduce delay in the event of symptoms of acute myocardial infarction.
\end{abstract}

\section{Introduction}

People having an acute myocardial infarction need to receive treatment as quickly as possible. ${ }^{1}$ Clinical trials have shown reductions in morbidity and mortality in patients treated with thrombolysis within one hour of the onset of symptoms. ${ }^{2-4}$ Delay by patients in seeking medical help, rather than the time from services being contacted to treatment being started in hospital, is the most significant cause of delay in treatment. ${ }^{5}$ The aim of this study was to explore patients' thoughts and feelings at the onset of symptoms of heart attack, their perceived reasons for deciding to seek medical help, and the things that delayed them in making this decision. We did this study with a view to improving the outcomes of educational interventions to reduce delay.

Many studies have investigated sociodemographic and clinical factors that predict delay, and some have examined the appraisal and knowledge of symptoms of acute myocardial infarction as a factor. ${ }^{6-11}$ This research has prompted interventions to improve people's knowledge of the symptoms of heart attack and the correct action to take when faced with these symptoms. However, the effectiveness of public awareness campaigns or education for patients in decreasing delays is uncertain. ${ }^{12}$ Some studies report that although such measures may increase knowledge, they are unlikely to change behaviour. ${ }^{13-15}$ Other studies report some reduction in the median time from onset of symptoms of acute myocardial infarction to arrival in hospital. ${ }^{16}{ }^{17}$ It has also been reported that patients with a second infarct take as long to seek help as those having their first one. Not all studies agree on this point, but there may be more to decision making than knowledge of the symptoms of heart attack. ${ }^{514}{ }^{18}$ For this reason, we studied patients who had had at least one previous acute myocardial infarction.

Department of
Health Sciences,
University of York,
Heslington, York
YO10 5DQ
Jill Pattenden
research fellow
Ian Watt
professor of primary
care
Robert J P Lewin
professor of
rehabilitation
Neil Stanford
research fellow
Correspondence to:
J Pattenden
jp30@york.ac.uk
bmj.com 2002;324:1006

\section{Methods}

We conducted the study in two district hospitals in North Yorkshire, which serve a mixed population, both urban and rural. Out of hours general practitioner services are mainly provided by three cooperative services. We obtained ethical approval from the two local research ethics committees.

\section{Participants}

We included patients with confirmed acute myocardial infarction who had had at least one infarction previously and were able to communicate in English. We excluded patients who had experienced cardiac arrest; patients who had severe heart disease or unstable angina; and patients who had a note in their case record of cognitive deficits, were unable to make daily decisions about their own care, or were in residential care.

Nursing staff gave an information sheet describing the study to eligible patients two to five days after admission to the coronary care unit. Semistructured interviews ranged from 30 minutes to over an hour, were conducted in a private room, and were audiotaped. If a partner or relative had been present during the decision making time they were interviewed separately from the patient. In two cases in which the patient had been discharged, interviews took place in the patient's home.

\section{Collection of data}

We asked participants to recount their experience of the heart attack. We also asked them about differences 
Sociodemographic characteristics and prehospital symptoms and behaviour of patients. Values are numbers (percentages) unless otherwise stated

\begin{tabular}{lc} 
Characteristics & $\begin{array}{c}\text { Patients } \\
(\mathbf{n}=\mathbf{2 2})\end{array}$ \\
\hline Male & $20(91)$ \\
\hline Living with spouse & $13(59)$ \\
\hline Alone at time of symptoms & $11(50)$ \\
\hline $\begin{array}{l}\text { Predominant symptoms perceived as typical of acute myocardial } \\
\text { infarction }\end{array}$ & $14(64)$ \\
\hline $\begin{array}{l}\text { Predominant symptoms not perceived as typical of acute } \\
\text { myocardial infarction }\end{array}$ & $8(36)$ \\
\hline Up to one hour taken to seek care & $11(50)$ \\
\hline One to four hours taken to seek care & $6(27)$ \\
\hline Over four hours taken to seek care & $5(23)$ \\
\hline $\begin{array}{l}\text { Symptoms initially different from those of previous acute } \\
\text { myocardial infarction }\end{array}$ & $20(91)$ \\
\hline Phoned ambulance directly & $8(36)$ \\
\hline Phoned general practitioner first & $12(55)$ \\
\hline Went to hospital by car & $1(5)$ \\
\hline Other & $1(5)$ \\
\hline Mean (SD) age years & $66(6.3)$ \\
\hline Median time (hours) from onset of symptoms to care being sought & 1.5 \\
\hline
\end{tabular}

between this and previous acute myocardial infarctions, the severity of symptoms, and whether they had perceived themselves to be at risk of an acute myocardial infarction. The data collected for each patient included a transcript of the interview, the interviewer's notes, and, where applicable, transcripts of interviews with family members who had been present at the time of the acute myocardial infarction. We analysed data from these relatives separately from the patients' accounts, but concurrently. We checked ambulance records for validation of reported times.

After each interview we analysed the new data and developed new codes and themes for use in subsequent interviews. Saturation of data, whereby no new and relevant material arose, was achieved by the time 22 interviews had taken place.

\section{Analysis of data}

The interviews were transcribed verbatim, and the interviewer verified the accuracy. We used constant comparative analysis. ${ }^{19}$ We coded data line by line, organised similar concepts into categories, and constantly compared these with concepts from earlier data to produce themes. The interviewer carried out the analysis; another member of the research team separately analysed 20\% of transcripts to compare coding and emerging themes. We resolved discrepancies through discussion. We also made comparisons across participants to determine similarities and variations.

\section{Results}

We collected and analysed data until no new themes arose. The stage at which data saturation was reached was decided by consensus within the research team.

Twenty men and two women participated in the study (table). In addition, two participants who met the inclusion criteria declined to participate. We also interviewed 10 spouses and one son who were present at the time of the event. Six themes emerged that seem to influence decision making processes (box 1). Each theme encompasses two or three interlinking and shared concepts.

\section{Appraisal of symptoms}

The appraisal of symptoms was a dynamic process throughout the decision making time. Identifying and labelling symptoms often posed problems, and many participants thought that their symptoms were not severe enough to be a heart attack. Instead of being "crushing chest pain," many heart attacks were reported to have had a slow onset with only mild pain and breathlessness. Many participants were confused by the fact that their symptoms were similar to angina or indigestion; many had experienced prodromal symptoms in the previous few days, which led to a normalising or minimising of symptoms (box 2). The use of glyceryl trinitrate spray may actually increase this confusion, as it seems to "lessen the pain a bit" and leave some people confused as to whether their pain represented angina or an acute myocardial infarction. Some people reported using glyceryl trinitrate many times more than recommended.

\section{Perceived risk of acute myocardial infarction}

Most patients who had always had a "healthy" lifestyle, or had changed their diet and smoking habit, and had had cardiac rehabilitation since their previous heart attack, thought that this would protect them from future cardiac problems (box 3). Some patients who had had a coronary artery bypass graft or percutaneous transluminal coronary angioplasty believed they were no longer at risk of an acute myocardial infarction. Thus some patients were bewildered as to the cause of their symptoms. People had tried to put their previous heart attack to the back of their mind and get on with life. Many of those who did not

Box 1: Factors influencing the time to action

- How symptoms are perceived and appraised

- Perceptions of risk of having an acute myocardial infarction

- Previous experience of symptoms of acute myocardial infarction

- Individual psychological or emotional factors

- Beliefs about the appropriate use of the NHS

- The context in which symptoms were experienced

\section{Box 2: Appraisal of symptoms}

Patient 14 -male, aged 62; second myocardial infarction. Previous infarction seven years previously. Two previous "false alarms," the second two weeks earlier. Decision time 13 hours.

"Well, I'd gone down town for a walk and I'd come back up town in the afternoon about, I think about 2 o'clock or something like that, and I had a slight chest pain. I didn't think too much of it because actually I had eaten some chips and I thought these chips had stuck in my chest, and you know, often when you get that sort of heartburny thing. But then it got to 5 o'clock and 6 o'clock and it went on till 10 o'clock and I still had this pain, but it started to get a wee bit worse and I put up with it until about three in the morning, and then I tried my spray a few times and that didn't work. I thought this can't be heartburn or indigestion or something, as those are the first things you think of obviously. I decided to ring the doctor." 


\section{Box 3: Perceived risk}

Patient 11-male, aged 71; third myocardial infarction. Previous infarctions three and six years previously. Decision time 30 minutes. Had severe pain in left arm and left side. Previous heart attack had involved central chest pain. He didn't think it could be another one. His wife took action.

"Because I believe you feel, it is not happening to me. Albeit that my sister died two years ago of a heart attack, my brother had a bypass operation ... but later on I have realised that you know, you've got a problem in your family. But my brother had been a heavy smoker you see and I don't, you know. My sister, god bless her, she was a fair heavy drinker and I don't drink, unless I go out for a meal. So you know my lifestyle is different ... Because you don't believe. You think no it can't be, especially in my case having had two bypass operations. I think well this can't happen, you see. But my wife had no hesitation after I had used the spray twice."

\section{Box 4: Previous experience}

Patient 16-male, aged 76; second myocardial infarction. First infarction three years previously. Decision time five hours.

"It was right across my chest. You see the last time I had a heart attack I was full of ... well I thought it was flatulence. I was trying to, burp you might say, almost continuously and this pain was nothing like that in that respect and that's why I thought, well, it's not a heart attack."

perceive themselves to be at risk reported taking longer to appraise symptoms and acted only when the pain or breathlessness became unbearable.

Previous experience of acute myocardial infarction Twenty (91\%) participants reported that the symptoms were not similar to those of any previous acute myocardial infarction (box 4). This usually slowed down the decision making process, as several participants were confused by the different symptoms. Several people reported that it was only when a symptom in common with the previous acute myocardial infarction occurred that they summoned medical help.

Six participants had previously experienced a "false alarm" (that is, they ascribed their symptoms to an acute myocardial infarction when this was not the case), but not all of them reported this as a factor that influenced their time to seek help. Those who said that they did not want to be embarrassed again by feeling "a fraud" reported a previous false alarm as having delayed their decision to seek help.

\section{Psychological factors and emotional response}

Many people did not want to believe that they were having a heart attack, tending to play down or ignore symptoms and wait until they became worse before seeking help. Even though many patients admitted to knowing that it was an acute myocardial infarction, they also admitted that, illogically, they "hoped it would go away" (box 5).

Fear and embarrassment at the possibility of being wrong in ascribing their symptoms to a heart attack, and even at having vomited, were also given as reasons for delay. Some patients seemed to find it difficult to relinquish control, wanting to manage the symptoms themselves and not go into hospital. These participants waited several hours in pain.

\section{Use of the NHS}

All participants apart from one felt a concern about wasting NHS time and resources, especially ambulances. It seems that many people do not want "to bother" the doctor, and they feel guilty about it (box 6). A common perception was that the correct action was first to phone a general practitioner, who would then get an ambulance. This perception may have been reinforced by ambulance services often asking whether a doctor had been called. Even those who had previously been told to phone an ambulance felt reluctant to do so, having a strong feeling that ambulances are for emergencies and that this was not an emergency. Some stated that if your general practitioner phones the ambulance, or tells you to, it gives you permission. Some patients also felt that their general practitioner would be quicker to get to them than an ambulance, knew them better, and would be "on their side."

\section{Context of the event}

The presence of another person seemed to influence the decision making process. For example, in some cases an increase in pallor was noticed by others, and, after discussion with the patient, the other person phoned for help (box 7). Also, if someone else phones, the patient feels less guilty about it, as responsibility is taken away. Several spouses reported the reluctance of their partners to "make a fuss," so the spouses made the decision.

\section{Box 5: Psychological factors}

Patient 21-male, aged 53; third myocardial infarction. Decision time seven hours.

"I appreciate the point, yes, why doesn't somebody admit what is happening? I don't know. Perhaps it is this fear of death and you say, if I am going to admit I am having a heart attack, I am going to admit I might be dying. And I don't want to admit that, so perhaps if I pretend it is not a heart attack, it might just go away and I might just be all right for a few more months." Interviewer: "Few more months?"

"You take months, you don't take years anymore! I don't know-I think that is it, it is a fear of admitting that you have got something which could kill you."

Patient 3-male, aged 75; second myocardial infarction. First infarction two months previously. Decision time two hours. He rang a relative and then waited until he got hold of him rather than ringing the ambulance, because of embarrassment at having vomited and being unable to climb the stairs to get a clean shirt. "This thing, dirty T-shirt, put me off ringing anybody. So if I had got a clean T-shirt I think I would have rung earlier. You worry about daft things really, don't you? What does it matter if I had torn it off and thrown it away? I didn't want to be stinking like that you see. Anyway he got me a T-shirt, my son-in-law, and I got it on before they came. I explained it all to them and they said we could have done it. My biggest trouble was the T-shirt. And I just didn't want to trouble anybody. I didn't want to be a bother." 


\section{Box 6: Use of the NHS}

Patient 4-male, aged 64; fourth myocardial infarction. Third infarction eight months previously. Decision time 30 minutes, which was much less than for the previous infarctions. He was still reluctant to bother services.

"Yeah, it's like being of the old school-you don't phone your doctor at weekends, I mean why not? It makes no blinking difference. Just because it's Saturday and Sunday, what difference does it make? It's still a day isn't it? It's a day and you're still poorly, you know, it's daft. But it's probably the only thing, you know damn well, you're probably not going to get your own doctor. They have a consortium."

Patient 13-male, aged 60; second myocardial infarction. Decision time nine hours. He tried to control the pain of the infarction, as he saw it as kind of continuum with angina at one end and heart attack at the other.

"I think the main thing is that you don't want to be a burden on anybody, well most men don't-you know and I think that if you go into hospital and you have to call an ambulance I still believe that dialling 999 is what it stands for-in emergency. I would never use it."

Interviewer: "You don't think you're an emergency?"

"Yes, it's when your brain's fit and clear you think it can't be that bad because I should be unconscious or not be able to speak and things like this, you know."

The time and place of the event seems to influence action. People were reluctant to seek medical help during the night and at weekends. Those who were not at home wanted to get back there to try to manage the symptoms or contact their own general practitioner, rather than going directly to hospital.

\section{Discussion}

This study helps to provide an understanding of the factors influencing the decision making process in people with symptoms of a heart attack. Analysis of the data provides a picture of the multiple realities and explanations in patients' accounts of their acute myocardial infarction, with six main themes that influence the decision to seek help emerging. The study did not set out to formally correlate the themes to the time taken before seeking medical help.

Qualitative research does not aim to produce findings that are generally transferable to other people. However, given that data were collected until saturation was reached and no new themes emerged, this study may highlight issues that are relevant to many patients who have had an acute myocardial infarction. The themes influencing decision time may also be applicable to patients experiencing a first acute myocardial infarction. However, the study had a low representation of women, and, although participants came from a broad range of socioeconomic backgrounds (as judged by profession and housing type), we cannot assume that other themes would not arise in other localities and cultural groups.

Although our findings are consistent with those of other studies in indicating that patients have difficulty recognising and evaluating symptoms ${ }^{20}$ this study adds to previous knowledge by showing that the decision to seek help is a complex interaction of knowledge and experience, beliefs, emotions, and the context of the event. This implies that knowledge of symptoms and of the correct action to take will not on its own shorten decision time. Yet interventions based around simple messages, mainly related to knowledge of symptoms and what to do in the event of these symptoms, are still being recommended..$^{21}$ Also, as this study found that most participants had different symptoms from those in their previous heart attacks, patients need to be warned that a future infarction might not be similar to the previous one. The frequency of atypical symptoms may increase with age. ${ }^{22}$

These findings might usefully inform strategies to reduce delay in seeking help in people having an acute myocardial infarction. Many factors influence the decision to seek help, and no single determinant seems to have overall primacy. This implies that interventions to reduce delay should be tailored to cover the six themes identified and should explore these factors with each patient individually. This may lead to more effective coping strategies in the event of acute myocardial infarction.

Such interventions could be carried out with patients before they are discharged from hospital. Because of the influence of other people in facilitating the decision to get help, family members and wardens of sheltered housing might usefully participate in these interventions. A similar approach in the primary care setting may be beneficial for people who are at risk but who have not yet had an acute myocardial infarction. The effects of such interventions will need to be evaluated.

\section{Box 7: Context}

Patient 4 -male, aged 64; fourth myocardial infarction. Decision time 30 minutes. He managed to explain thoughts expressed by many other patients-that if someone else is with you, it not only reduces fear but also takes away the responsibility of the decision.

"Well I didn't delay any longer than I was told, I must admit. As I said, you do get a little bit frightened, you know, on your own. If there was somebody there with you, somebody to hold your hand, I don't think it would be as bad. I think it is the most frightening time I ever had anyway, when I've had these heart attacks, is when I've been on my own."

Interviewer: "So the first two, really being with people, you weren't so scared ..."

"They took the decision for me, so it was nice that somebody takes the decision away from you, because if you have somebody there and obviously they didn't take the decision for you, you'd get going, you'd get on the phone. But if they do it, you'd probably play hell with them and say 'oh, I don't need to be fussing with an ambulance,' you know, but it's sensible. Well, I mean, I'm very ... I don't rush into things, when I should, I mean, I know I should, but I don't."

Patient 2-male, aged 69; second myocardial infarction (in the early hours of the morning). First infarction eight years previously. Decision time one hour.

"It's just a question of well, what shall I do, shall I just rest and wait and see if it goes off? If it goes off, I had better get a nice rest and then tell the doctor on the following day. Or should I? If it is a heart attack should I ring somebody and go and get some help, now, even though it does go off? At that time in the morning, you think, well no I'll just wait and see and just leave it a bit." 


\section{What is already known on this topic}

Individual sociodemographic and clinical characteristics affect the time to seeking medical care in patients with symptoms of acute myocardial infarction

Appraisal of symptoms is difficult; people with classic and severe symptoms are more likely to take prompt action

\section{What this study adds}

The decision to seek medical help in patients who have had one or more previous myocardial infarctions is a complex process

Simply providing patients with information on symptoms of acute myocardial infarction, and what to do in the event of these symptoms, may not be sufficient to promote prompt action

\section{Conclusion}

This study shows that the decision to seek medical help by patients who have had one or more acute myocardial infarctions is a complex one, and it is not simply influenced by knowledge of symptoms or of the correct actions to take. We identified six main themes that seem to influence decision making: appraisal of symptoms, perceived risk of acute myocardial infarction, previous experience of myocardial infarction, psychological and emotional factors, beliefs about correct use of NHS resources, and the context of the event. Consideration of these themes in interventions to promote prompt action by people having an acute myocardial infarction may enhance effectiveness and lead to reductions in morbidity and mortality.

We thank staff on coronary care units at both hospitals.

Contributors: JP was the principal researcher, collected and analysed the data, wrote the first draft of the paper, and will act as guarantor of the paper. IW gave ongoing support to the project and participated in writing the paper. RL provided ongoing advice and support to the project, reviewed aspects of interpretation of data, and contributed to editing the paper. NS reviewed the coding and interpretation of data and contributed to editing the paper.

Funding: North Yorkshire Health Authority. The British Heart Foundation funded the original "HeartSave" scheme that prompted this research.

Competing interests: None declared.

1 ISIS-2 (Second International Study of Infarct Survival) Collaborative Group. Randomised trial of intravenous streptokinase, oral aspirin, both, or neither among 17,187 cases of suspected acute myocardial infarction: ISIS-2. Lancet 1988;ii:349-60.

2 Gruppo Italiano per lo Studio della Streptochinasi nell'Infarto Miocardico (GISSI). Effectiveness of intravenous thrombolytic treatment in acute myocardial infarction. Lancet 1986;: $: 397-402$.

3 Berger PB, Bell MR, Holmes DR, Gersh BJ, Hopfenspirger M, Gibbons R. Time to reperfusion with direct coronary angioplasty and thrombolytic therapy in acute myocardial infarction. Am J Cardiol 1994;73:231-6.

4 Fibrinolytic Therapy Trialists' (FTT) Collaborative Group. Indications for fibrinolytic therapy in suspected acute myocardial infarction: collaborative overview of early mortality and major morbidity results from all randomised trials of more than 1000 patients. Lancet 1994:343:311-22.

5 Dracup K, Moser DK, Eisenberg M, Meischke H, Alonzo AA, Braslow A. Causes of delay in seeking treatment for heart attack symptoms. Soc Sci Med 1995;40:379-92.

6 Goldberg RJ, Gurwitz J, Yarzebski J, Landon J, Gore JM, Alpert JS, et al. Patient delay and receipt of thrombolytic therapy among patients with acute myocardial infarction from a community-wide perspective. $A m J$ Cardiol 1992:70:421-5.

7 Goff DC, Sellers DE, McGovern PG, Meischke H, Goldberg RJ, Bittner V, et al. Knowledge of heart attack symptoms in a population survey in the United States: the REACT trial. Rapid early action for coronary treatment. Arch Intern Med 1998;158(21):2329-38.

8 Goff DC, Feldman HA, McGovern PG, Goldberg RJ, Simons Morton DG, Cornell CE, et al. Prehospital delay in patients hospitalized with heart attack symptoms in the United States: the REACT trial. Am Heart J 1999;138:1046-57

9 Ruston A, Clayton J, Calnan M. Patients' action during their cardiac event: qualitative study exploring differences and modifiable factors. BMJ 1998;316:1060-4.

10 Horne R, James D, Petrie K, Weinman J, Vincent R. Patients interpretation of symptoms as a cause of delay in reaching hospital during acute myocardial infarction. Heart 2000;83:388-93.

11 McKinley S, Moser DK, Dracup K. Treatment-seeking behavior for acute myocardial infarction symptoms in North America and Australia. Hear Lung 2000;29:237-47.

12 Blohm MB, Hartford M, Karlson BW, Luepker RV, Herlitz J. An evaluation of the results of media and educational campaigns designed to shorten the time taken by patients with acute myocardial infarction to decide to go to hospital. Heart 1996;76:430-4.

13 Ho MT, Eisenberg MS, Litwin PE, Schaeffer SM, Damon SK. Delay between onset of chest pain and seeking medical care: the effect of public education. Ann Emerg Med 1989;18:727-31.

14 Meischke H, Dulberg EM, Schaeffer SS, Henwood DK, Larsen MP, Eisenberg MS. "Call fast, call 911": a direct mail campaign to reduce patient delay in acute myocardial infarction. Am J Public Health 1997;87:1705-9.

15 Luepker RV, Raczynski JM, Osganian S, Goldberg RJ, Finnegan JR, Hedges JR, et al. Effect of a community intervention on patient delay and emergency medical service use in acute coronary heart disease: the rapid early action for coronary treatment (REACT) trial. JAMA 2000;284:60-7.

16 Gaspoz JM, Unger PF, Urban P, Chevrolet JC, Rutishauser W, Lovis C, et al. Impact of a public campaign on pre-hospital delay in patients reporting chest pain. Heart 1996;76:150-5.

17 Herlitz J, Blohm M, Hartford M, Karlson BW, Luepker RV, Holmberg S, et al. Follow-up of a 1-year media campaign on delay times and ambulance use in suspected acute myocardial infarction. Eur Heart 1992;13:171-7

18 Rustige J, Schiele R, Burczyk U, Koch A, Gottwik M, Neuhaus KL, et al. The 60 minutes myocardial infarction project. Treatment and clinical outcome of patients with acute myocardial infarction in Germany. Eur Heart J 1997; 18:1438-46.

19 Strauss A, Corbin J. Basics of qualitative research: grounded theory procedure and techniques. Newbury Park, CA: Sage, 1990.

20 Dracup K, Moser DK. Beyond sociodemographics: factors influencing the decision to seek treatment for symptoms of acute myocardial infarction. Heart Lung 1997;26:253-62.

21 Department of Health. National service framework for coronary heart disease. London: Stationery Office, 2000.

22 Roupie E. L'infarctus du myocarde au service d'accueil et d'urgences: une entite particulière ou la prédominance des atypies?... [Myocardial infarct in the admissions and emergency service: a particular entity or predominant atypia?.... Presse Med 1998;27:1636-7.

(Accepted 29 November 2001) 